\title{
Initial Inoculum and Spatial Dispersal of Colletotrichum gloeosporioides, the Causal Agent of Strawberry Anthracnose Crown Rot
}

\author{
Mahfuzur Rahman, Peter Ojiambo, and Frank Louws, Department of Plant Pathology, North Carolina State University, Raleigh 27695
}

\begin{abstract}
Rahman, M., Ojiambo, P., and Louws, F. 2015. Initial inoculum and spatial dispersal of Colletotrichum gloeosporioides, the causal agent of strawberry anthracnose crown rot. Plant Dis. 99:80-86.

Anthracnose crown rot (ACR), caused by Colletotrichum gloeosporioides, is a serious disease of strawberry (Fragaria $\times$ ananassa) in nurseries and fruiting fields in the southeastern United States. This study was conducted to determine the potential of alternative hosts for initial inoculum source and spread that causes ACR in strawberry nurseries. Results indicated that Parthenocissus quinquefolia is a noncultivated host of $C$. gloeosporioides in North Carolina and may serve as an initial inoculum source for planting material. Sources of inoculum data were complemented with a 2-year study of disease incidence and spread in simulated nursery production experiments. Sixty days after inoculation of the mother plants in the nursery, three different inoculation levels showed a significant positive correlation $(r=0.78, P$ $<0.004)$ with the quiescent infection $(\mathrm{QI})$ incidence on the runner or daughter plants at the end of the nursery production cycle. Runner plant counts from different proportion of mother plants' inoculation

treatments indicated that runner plant production was negatively and significantly $(P<0.001)$ affected by $C$. gloeosporioides. Infected tips used to produce transplants destined for fruit production resulted in 29.3 and $16.8 \%$ mortality in plug trays in 2007 and 2008, respectively. Tracking foliar QI incidence that resulted from dispersal of inoculum from an introduced point source in the nursery showed a sharp decline at $1 \mathrm{~m}$ and beyond from the inoculation focus. Although the exponential model $\left(R^{2}=0.92\right.$ to 0.94$)$ had slightly higher coefficients of determination than the modified power law $\left(R^{2}=0.89\right.$ to 0.90$)$, residual plots indicated that the modified power law model fit the disease gradient data better than the exponential model in both years. Results from our dispersal study indicated that rogueing of infected plants within a 4- $m$ radius of infection foci would reduce the risk of transferring infected runner plants from the nursery to the fruiting field.
\end{abstract}

Anthracnose crown rot (ACR), caused predominantly by Colletotrichum gloeosporioides $(19,42)$ and, to a lesser extent, by $C$. fragariae $(5,18)$ and $C$. acutatum $(20)$, caused significant losses to strawberry nursery and fruit growers in recent years in the southeastern United States (SE), where warm, moist conditions and abundant rainfall favor growth and rapid dissemination of the pathogen. Although $C$. acutatum and $C$. fragariae sometimes are involved with ACR, C. gloeosporioides causes most of the ACR observed in this region $(19,23)$, and the pathogen is isolated most commonly from crowns of wilted plants both in the nursery and fruiting field. It is possible that many if not all C. gloeosporioides isolates from strawberry were described as $C$. fragariae prior to the updated species definition of Gunnell and Gubler (17). In addition, many investigators do not agree that $C$. fragariae is a different species because of the genetic relatedness among different strains of C. gloeosporioides and C. fragariae $(7,19,27,40,41)$.

C. gloeosporioides can kill strawberry plants by aggressively invading and producing a reddish-brown to marbled orange necrosis of crown tissue that causes the plant to collapse. Although inoculum sources for plants in fruiting fields can be diverse, nonsymptomatic infected (quiescent or latent) planting stock is one of the most important sources of inoculum $(22,37)$. Quiescent infection (QI) is defined as a period during which an infection is present but not active within a host and may remain asymptomatic. QI is primarily attributed to the presence of preformed antifungal compounds in host tissues, activation of induced resistance, or a com-

Corresponding author: M. Rahman, E-mail:mmrahman@mail.wvu.edu

Current address of M. Rahman: WVU Extension Service, West Virginia University, Morgantown 26506.

Accepted for publication 19 June 2014.

http://dx.doi.org/10.1094/PDIS-02-13-0144-RE

(C) 2015 The American Phytopathological Society plex series of physiological and biochemical interactions between the pathogen and the host (34). ACR incidences in the SE during the last several cropping seasons revealed the association of the problem with asymptomatic plants imported from transplant supply nurseries, either as tips or bare root plants (F. Louws, personal observation), although a study in Florida indicated that alternative noncultivated hosts might have been the source of inoculum in the fruiting field (45). The use of "disease-free transplants" is the first and most effective method for controlling ACR in fruit production fields (26) because popular cultivars used in this region are mostly susceptible to $C$. gloeosporioides and cultivars with complete resistance to ACR are unknown (10,39). Although ACR is observed in fields during the winter and spring production season, it is most severe in summer nurseries in the SE, when prolonged high temperature and relative humidity is a phenomenon with frequent rains or thunderstorms. Symptom expression is much more severe during the high temperatures (38) of summer months in a polycyclic development of an epidemic, although many of the infected plants may remain asymptomatic. These plants, when procured by states in the SE and planted in fruiting fields under sprinkler, fail to establish due to spread of inoculum and crown infections (25).

In order to minimize the impact of using potentially infected plants from nurseries for fruit production in the field, North Carolina State University (NCSU) developed a certified nursery plant production industry in North Carolina. Initial plant sources for these certification nurseries are virus-indexed and tissue-culturederived plantlets. Plants are multiplied through cycles in the foundation, registered, and eventually in the certification nurseries. Thus, initial infection likely occurs in one of these nurseries and spreads due to secondary dispersal. Information on inoculum sources and dispersal potential would help growers determine the effectiveness of rogueing the infected plants as a management tactic. Nursery growers incur a heavy loss if they have to destroy large areas of planting materials due to the presence of C. gloeosporioides. There is no current protocol available to the growers regarding how to deal with these plants. 
A clear understanding of results from empirical studies on inoculum dispersal distance from a point source (i.e., infected plant) in the nursery should be an indication of risk and the extent of rogueing of infected plants or treatments required. Liberation of conidia by rain water drops (splash) on infected tissue followed by wind dispersal was documented as the major mechanism of $C$. gloeosporioides inoculum spread for strawberry $(31,32)$ as well as onion (36), rice $(46,47)$, and mango (14).There is very limited information available on the initial source of $C$. gloeosporioides infection in strawberry nurseries and how it is spread during the nursery production cycle in North Carolina. The objectives of this research were to (i) identify alternative sources of inoculum and their importance in the epidemic, (ii) assess the impact of mother plant infection on runner plant health and plug mortality, and (iii) assess spatial dispersal of inoculum within the nursery that could lead to determining rogueing distance or other management practices.

\section{Materials and Methods}

Isolates from alternative hosts and pathogenicity assays on strawberry. In total, 250 leaves from each of five different species (50 leaves/species) of potential alternative noncultivated hosts (Table 1) were collected from around strawberry fields at the Horticultural Crops Research Station, Castle Hayne $(\mathrm{CH})$, NC in spring 2008. Strawberry plants at this location showed mortality in 2007 due to C. gloeosporioides as diagnosed by the NCSU Plant Disease and Insect Clinic (NCSU-PDIC). Another set of 250 leaf samples from the same five species of possible alternative noncultivated hosts was collected in 2009 from the periphery of a strawberry nursery located at Sandhills $(\mathrm{SH}), \mathrm{NC}$, which also showed a high incidence of infected plants. Selection of the species of noncultivated hosts was based on a previous study conducted in Florida (45) and prevalence of the species within a 50-m perimeter of the locations. Field and nursery were divided into five equal transects and 50 leaves were collected from each transect within the field or within the lines that extended up to $50 \mathrm{~m}$ outside the field. Leaves were then subjected to a paraquat protocol (8). Briefly, induction of senescence to surface-sterilized leaves was achieved by dipping in paraquat followed by 7 days of incubation on metal screens inside a humid chamber layered with moist paper towel to enhance acervular growth. Spore masses from the leaf surface were streaked on potato dextrose agar (PDA; Difco, Lawrence, KS) and single-spore colonies were transferred to separate slants. Each isolate was identified by microscopic study of the spore morphology as well as with PCR using a species-specific internal transcribed spacer region (ITS1) primer CgInt (GGCCTCCCGCCTCCG GGCGG) and the conserved universal primer ITS4 (5'TCCTCCGCTTATTGATATGC-3') encoded in the 28S ribosomal subunit. Extraction of DNA and PCR amplification was performed according to the methods described by Mills et al. (27). Pathogenicity of the $56 \mathrm{C}$. gloeosporioides isolates recovered from noncultivated hosts was evaluated on the susceptible strawberry 'Chandler' in the greenhouse. Conidial suspensions were made from 10-day-old PDA cultures grown at $24^{\circ} \mathrm{C}$ under intermittent fluorescent light and adjusted to $5 \times 10^{6}$ conidia/ml in sterile de- ionized water. Sixty-day-old plug plants grown in pots were sprayed with each isolate on foliage up to run-off. There were five replicate plants per isolate. The plants were covered with plastic bags immediately after spraying for $72 \mathrm{~h}$ to maintain high humidity for spore germination and infection. Two plants were sprayed with sterile deionized water only as negative controls. Two C. gloeosporioides strawberry isolates of known pathogenicity were included as a positive control. Each isolate was tested twice under the same greenhouse conditions. Pathogenicity of $C$. gloeosporioides isolates against strawberry plants in this study was considered as any abnormality (wilting due to ACR, stunting, or black spots on leaves) caused by isolates compared with a noninoculated healthy plant of the same age. Symptomatic plants in each trial were placed in one of the three groups (highly pathogenic $=$ total wilting of plants 6 weeks after inoculation, moderately pathogenic $=$ needed exposure to high temperature for ACR and whole-plant wilting, or weakly pathogenic $=$ only caused stunting of the plants but no wilting) as a surrogate variable for aggressiveness. Reisolations of $C$. gloeosporioides from each symptomatic plant were done from either the crown or the leaf.

Nursery establishment. In order to study the dispersal of $C$. gloeosporioides from mother to daughter plants in time and space, a strawberry nursery was established at the Horticultural Crops Research Station, Clinton, NC by using fresh-dug bare-root mother plants from the NCSU certification program in 2007 and 2008. Plots were fumigated with metam sodium (Vapam HL; Amvac Chemical Corporation, Los Angeles) at 230 liters/acre after land cultivation, and the top soil layer was sealed by sprinkling $0.75 \mathrm{~cm}$ of water immediately after shank injection of the product. Plot size was 6.1 by $6.1 \mathrm{~m}$ with five rows spaced at $1.1 \mathrm{~m}$ apart; plants were spaced $0.5 \mathrm{~m}$ apart in each row. Plots were kept separated by a 1.5$\mathrm{m}$ aisle planted with pearl millet to prevent cross contamination. Planting was done with a hand-held notched planting tool that pushed root systems straight down into the soil as needed, avoiding formation of J roots. Root tips of J-root plants may remain exposed above ground, affecting proper establishment. Plants were watered with an overhead sprinkler for 7 days every day from 10:00 a.m. to 5:00 p.m. to aid establishment. Planting dates were 14 May 2007 and 23 April 2008. Standard industry practices for production were done as needed.

Inoculum preparation and treatment applications in the nursery. Three cultures of C. gloeosporioides (07-2633, 07-3063, and 07-3089) previously isolated from strawberry plants showing severe ACR symptoms were obtained from the NCSU-PDIC. The single-spore cultures were grown for 7 days under intermittent fluorescent lighting in petri plates containing PDA (PDA at 39 $\mathrm{g} / \mathrm{liter}$ and streptomycin sulfate at $25 \mathrm{mg} / \mathrm{liter}$ ). Conidia were collected by adding $15 \mathrm{ml}$ of sterile $\mathrm{dH}_{2} \mathrm{O}$ to each plate and scraping gently with a bent glass rod. The conidial suspensions were combined, quantified using a hemocytometer, and diluted to $1 \times 10^{5}$ conidia/ml. The selected plants in each plot were spray inoculated to run-off 70 and 82 days after planting in 2007 and 2008, respectively. Immediately after inoculation, the plants were covered with clear plastic bags for $72 \mathrm{~h}$, ensuring an environment conducive to spore germination and infection. There were four treatments where

Table 1. Isolates of Colletotrichum gloeosporioides recovered from noncultivated hosts at two different sites in North Carolina and pathogenicity on strawberry plants ${ }^{\mathrm{x}}$

\begin{tabular}{|c|c|c|c|c|}
\hline \multirow[b]{2}{*}{ Host (botanical name) } & \multicolumn{2}{|c|}{ Number of isolates ${ }^{y}$} & \multicolumn{2}{|c|}{ Pathogenicity to strawberry ${ }^{z}$} \\
\hline & $\mathbf{C H}$ & SH & CH & SH \\
\hline Virginia creeper (Parthenocissus quinquefolia) & $10(3)$ & $15(4)$ & +++ & +++ \\
\hline Noncultivated/Muscadine grape (Vitis/Muscadinia rotundifolia) & $5(1)$ & $8(2)$ & ++ & ++ \\
\hline Smilax (Smilax rotundifolia) & 0 & $10(1)$ & - & + \\
\hline Chickweed (Stellaria media) & 0 & 5 & - & - \\
\hline Brazil pusley (Richardia brasiliensis) & 0 & 3 & - & - \\
\hline
\end{tabular}

${ }^{\mathrm{x}} \mathrm{CH}=$ Castle Hayne, $\mathrm{NC}$ and $\mathrm{SH}=$ Sandhills, NC.

${ }^{\mathrm{y}}$ The number of isolates collected and verified using morphological and molecular methods; those pathogenic to strawberry are given in parentheses.

${ }^{\mathrm{z}}$ Symbols: $+++=$ highly pathogenic, $++=$ moderately pathogenic and needed exposure to high temperature $\left(32^{\circ} \mathrm{C}\right)$ for anthracnose crown rot and wholeplant wilting, and $+=$ caused only stunting of the plants but no wilting. $-=$ not pathogenic on strawberry. 
$0,5,10$, and $25 \%$ of the mother plants in each plot were inoculated. Treatments were arranged using a randomized complete block design with four replications. Thus, $0,5,10$, and $25 \%$ treatments had a total of $0,12,24$, and 60 inoculated plants. Plants were selected for inoculation in each plot by TFPlan software for restricted randomization (4). In addition, four plots under similar settings had only one plant inoculated at each plot for spatial dispersal studies. Four strawberry plants were also maintained in pots in all four sides of the experimental plot more than $10 \mathrm{~m}$ away from the inoculum source to assess the background exposure of inoculum from surrounding sources. These plants in pots were watered and managed separately to avoid any cross contamination from inoculated plots.

Sampling and evaluation of QIs. In all, 40 leaf samples from the mother and 40 leaf samples from runner plants in each plot were collected at 60 days after inoculation (DAI). Two middleaged leaves (fully open and $>20$ days old) were collected from each mother plant regardless of the inoculation status whereas leaf samples of similar age from daughter plants were taken from the plants located at the middle of rows, equidistant from mother plants. Similar but smaller (20 leaves/plot) leaf sampling was also done from only inoculated mother plants at 30 DAI. Leaf samples were evaluated for the presence of QI by the paraquat assay. Incidence was determined by the appearance of acervuli on the adaxial side of a leaf visible at $\times 5$ magnification after 7 days of incubation. Selected spore masses were evaluated at higher magnification to verify the presence of diagnostic spores (17). Severity of QI was measured as the area covered by acervular growth through visual assessment complemented with the use of a sample grid and compared with the total leaf area expressed as percent leaf area.

Data analysis. Data on C. gloeosporioides QI incidence and severity in mother and runner plants from nursery were transformed using angular transformation (arcsine of square-rooted proportion) prior to analysis to satisfy the assumption of normality and data back-transformed for presentation in the text. Data were subjected to two-way analysis of variance, where treatment, experimental repeats from 2007 and 2008 as trial, and treatment-trial were considered as fixed effects and block was considered as a random effect. Trial was significant $(P=0.007)$ in the analysis of variance and, thus, subsequent analyses was performed and presented separately for each year.

Plug production with infected tips. Plug production refers to the grow-out of strawberry transplants in multicell propagation trays starting with unrooted tips cut from mother plant runners in the nursery. After 4 to 5 weeks, plants grow a mass of roots (plugs) that can be field set in fruiting fields. In total, 100 tips from the $25 \%$ inoculated and another 100 from control treatments in the nursery experiment were collected 50 days after mother plants were inoculated. Plug plants were produced under mist in a greenhouse condition following Durner et al. (11) to determine the potential risk to fruit growers if quiescently infected tips are used for plug production. Plug mortality was recorded every 7 days from plug setting to planting in the field. Plug trays were separated with polyethylene barriers to prevent splash dispersal of inoculum from inoculated treatment to control treatment tips in the greenhouse.

Effect of inoculation levels on runner plant production in the nursery. Total numbers of runner plants were counted from two arbitrarily selected $1-\mathrm{m}$ quadrats at the center of each plot prior to digging bare-root runner plants. Total numbers of dead mother plants also were counted at the same time from different plots. Reisolation of $C$. gloeosporioides from the crown of dead plants was done to verify the cause of plant mortality. Briefly, crowns of dead or dying plants were cut longitudinally with a clean sterile scalpel. Symptomatic crown tissue pieces measuring 0.5 by 0.5 by $2 \mathrm{~mm}$ was excised and placed in PDA plates supplemented with streptomycin sulfate. Longitudinally cut crown pieces also were incubated in a moist chamber layered with paper towels. C. gloeosporioides conidia were identified on slide mounts at $\times 400$ magnification using a compound microscope.

Data analysis. The linear mixed-model (MIXED) procedure of SAS software (version 9.2; SAS Institute Inc., Cary, NC) was used to conduct the analysis of variance for repeated data from plug mortality. Trials in 2007 and 2008 were considered fixed effect whereas block and time of counts were random effects with autoregressive covariance structure. Correlations between percent inoculation and QI incidence and severity at 30 and 60 DAI were determined by using Pearson's correlation in SAS using the CORR procedure. A regression analysis of number of runner plants on levels of mother plant inoculation was performed to determine how various inoculation levels affected runner plant production in nursery plots.

Estimation of spatial dispersal gradient. In all, 50 leaf samples (10 from each of the 0-, 1-, 2-, 3-, and 4-m distances from the initial inoculum source) were taken at 60 DAI. Leaf samples also were taken from plants that were maintained in pots more than 10 $\mathrm{m}$ away from the inoculum source. Leaves were evaluated for QI as described previously. QI incidence was calculated from the ratio of positive samples compared with the total number of samples collected at each sampling distance. Incidence at distance zero was considered as the initial source for inoculum dispersal.

Two models that can describe disease incidence at the source were fit to the disease gradient data. The modified Gregory model (29), commonly referred to as the modified power law, was expressed as $y=a(x+c)^{-b}$, in which $y$ is the number of QI incidence due to effective spore dispersal to a distance from the point source, $a$ is the amount of inoculum present per unit area at $1-c$ units from the source, $b$ is the unit-less slope of the gradient, and $x$ is the distance from the center of the source to the center of a sampling unit. The parameter $c$ is an offset parameter that allows the power law to have a finite value at $x=0$ (6) has been shown to be approximately equal to the source (29). In this study, the average radius of the canopy diameter of an inoculated plant was used as the value of $c$.

The second model fit to the data, the Kiyosawa and Shiyomi (19), commonly referred to as the exponential model, was expressed as $y=a \exp (-b x)$, in which variables $y$ and $x$ and the parameters $a$ and $b$ are as defined for modified power law.

Data analysis. Linear regression analyses were performed separately for 2007 and 2008 data using REG procedure in SAS (version 9.2; SAS Institute Inc.). To allow for logarithmic transformation of the data, zero observations for disease data were replaced with the smallest nonzero observation in the data set (i.e., $0.01)$ prior to the analysis. Parameters in the modified power law model were estimated using the REG procedure in SAS by regressing $\ln (y)$ on $\ln (x+c)$, where $\ln$ is the natural logarithm. In this regression, the slope of the regression is the estimate of $b$ and the antilog (base e) of the intercept provides an estimate of $a$. Parameters in the exponential model were also estimated by linear regression of $\ln (y)$ on $x$, where the slope of the regression is the estimate of $b$ and the antilog of the intercept is the estimate of $a$. The fit of the two models to the disease gradient data was assessed based on simple correlation of observed and predicted values, the plots of the residuals versus $\ln (x)$, and coefficients of determination.

\section{Results}

Isolates from alternative hosts and pathogenicity assays on strawberry. C. gloeosporioides isolates were recovered from five and two noncultivated hosts at the $\mathrm{SH}$ and $\mathrm{CH}$ sites, respectively. In addition, with a lower number of noncultivated species with positive samples, the $\mathrm{CH}$ site also had lower disease severity. The SH site noncultivated hosts had higher disease severity, and more isolates originated from this site were found to be pathogenic on strawberry host in the greenhouse assay (Table 1) compared with the $\mathrm{CH}$ site. Overall, only $20 \%$ of isolates collected from alternative hosts were pathogenic to strawberry. Isolates from chickweed (Stellaria media) and Brazil pusley (Richardia brasiliensis) were not pathogenic to strawberry. Irregular black lesions were visible on strawberry leaves after inoculation with the pathogenic isolates from Virginia creeper (Parthenocissus quinquefolia). Crown discoloration and plant wilting occurred 6 weeks after inoculation Muscadine grape (Vitis/Muscadinia rotundifolia) isolates also produced typical leaf and crown symptoms but plant wilting took 
more than 8 weeks, and required incubation at a high temperature $\left(32^{\circ} \mathrm{C}\right)$ in a growth chamber. The smilax (Smilax rotundifolia) isolate caused only stunting and the affected plants never showed wilting symptoms, indicating the variation in aggressiveness of isolates originated from different alternative hosts.

QIs on mother and runner plants. Due to the timing (during sunset) of inoculation followed by covering the plants with plastic bags, inoculation efficiency was $100 \% 7$ DAI. Levels of QI incidence on both mother and runner plants in both years reached $\geq 70 \%$ in $25 \%$ mother-plant-inoculated plots at $60 \mathrm{DAI}$, with slightly higher incidence in 2007 than 2008 (Fig. 1A and B). Infection incidence on runner plants was the same or a little higher than the level on mother plants but severity on runner plants was considerably lower compared with that of mother plants in both years (Fig. $1 \mathrm{C}$ and D). Control plots had the lowest incidence and severity of C. gloeosporioides on the mother plants. However, incidence on both mother and runner plants in 2008 was higher compared with 2007, and runner plant QI incidence in 2008 was statistically similar to the 5\% level inoculation. Overall QI incidence in control plots was higher in 2008 than in 2007, whereas it was higher in 2007 than 2008 in inoculated plots (Fig. 1A and B). At 30 DAI, combined QI incidence data from 2007 and 2008 showed a strong significant correlation $(r=0.92, P<0.001)$ with percent mother plants inoculated, which reduced over time $(r=0.78, P<0.004)$ at 60 DAI. Severity of QI on runner plant leaves showed a similar strong significant correlation $(r=0.96, P<0.038)$ with level of inoculation in 2007. However, correlation of QI severity of runner plant leaves in 2008 and mother plant leaves in both years with level of inoculation was relatively weak (data not shown). In inoculated plots, overall severity on mother plants showed a weaker correlation with percent inoculation compared with runner plants at 60 DAI. In 2007, maximum average leaf area covered by acervular growth was $6.7 \%$ in mother plants compared with only $3.7 \%$ in runner plants. Plants grown in the pot $10 \mathrm{~m}$ away from the experiment site did not have any QI on foliage, indicating that background exposure of inoculum from surrounding sources was negligible.
Plug production with infected runner tips. None of the tips from noninoculated control plots died during 30 days of the plug production period despite some minor QI incidence and severity recorded on nursery leaves using the paraquat assay (Fig. 1). Plug mortality in 2008 was significantly lower compared with that in 2007. After 30 days of plug setting, 29\% of plugs collapsed or wilted in 2007 compared with $16.8 \%$ in 2008 (Fig. 2). This difference in plug mortality likely reflects the difference in QI incidence and severity in 2007 and 2008. However, the trend in disease progression was similar in both years.

Effect of inoculation proportion on number of runner plants produced. Variation in the proportion of mother plant inoculation significantly influenced total number of runner plants produced per unit area in the nursery in both years. Average runner plant produc-

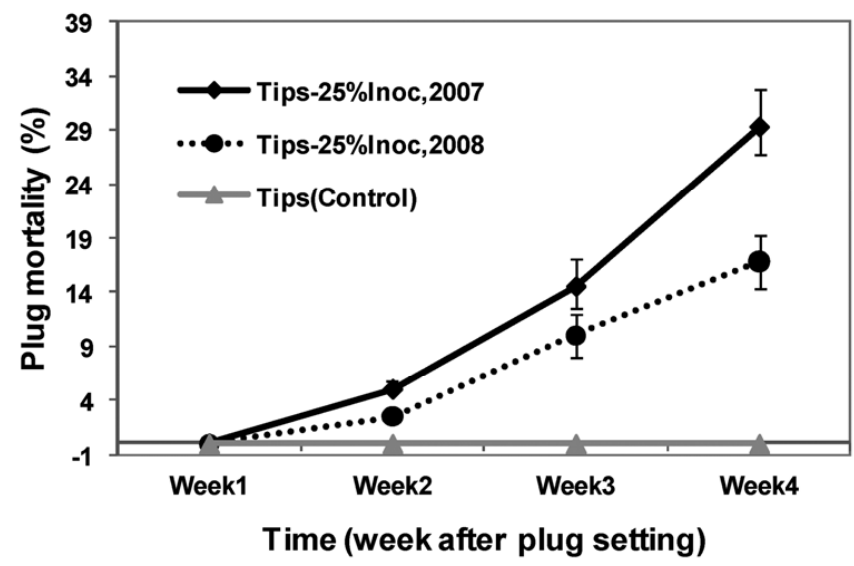

Fig. 2. Plug mortality progression in the greenhouse plug plant production system from potentially infected tips collected from $25 \%$ mother plant inoculation level in the nursery. Vertical lines are the standard errors of means. None of the tips were symptomatic at the time of collection.
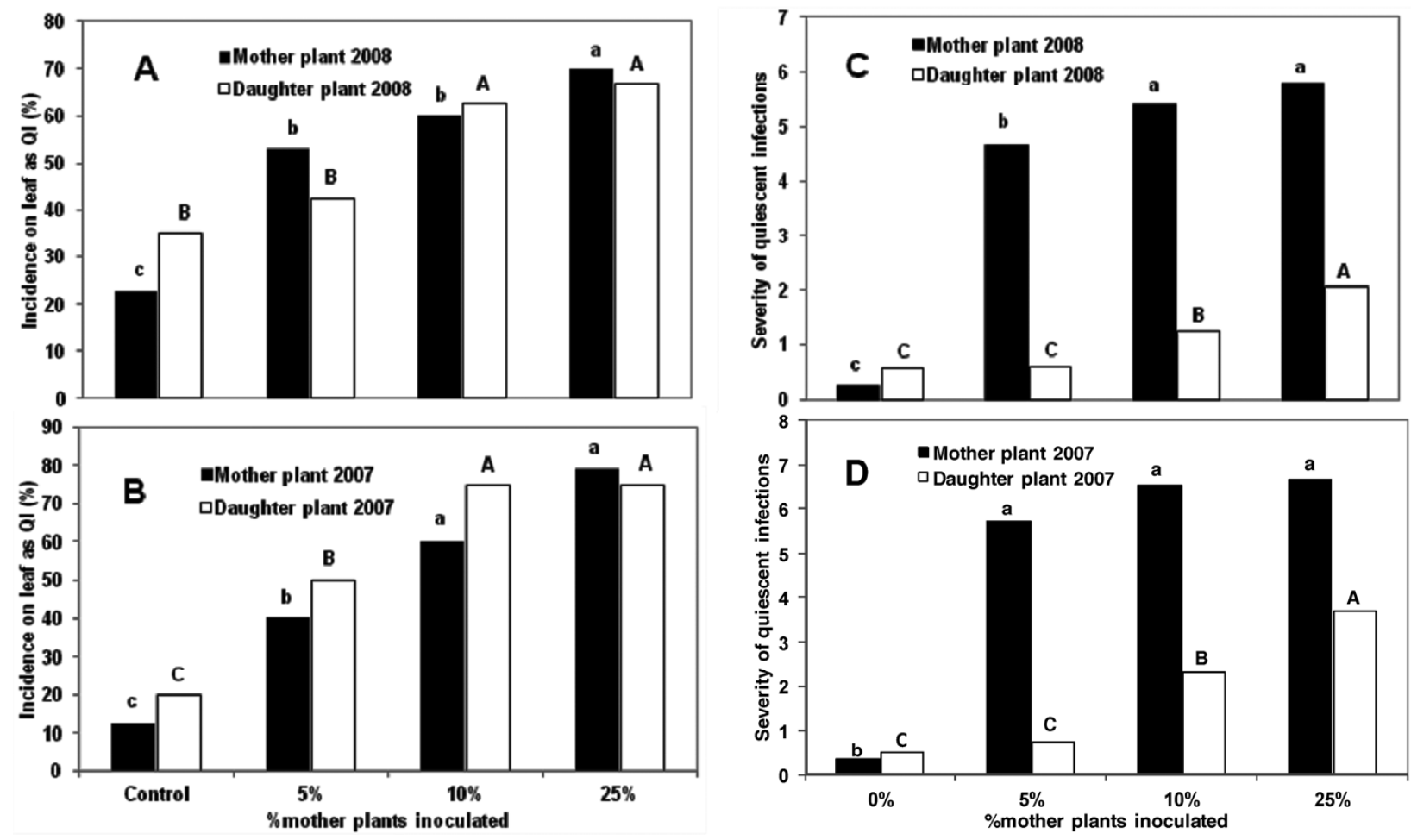

Fig. 1. Incidence and severity of quiescent infections (QIs) in each treatment as determined by the paraquat dip method from leaves $(n=160)$ sampled at 60 days after inoculation of mother plants by spraying Colletotrichum gloeosporioides conidial suspension ( 1 × $10^{5}$ conidia/ml) on foliage. Data from 2007 and 2008 were analyzed separately for incidence and severity to compare mother plant and runner plant. Vertical bars represent means of QI $\mathbf{A}$ and $\mathbf{B}$, incidence and $\mathbf{C}$ and $\mathbf{D}$, severity from 40 leaves collected from each of four replicate plots. Bars with the same letter (lower case for mother and upper case for runner) on the top are not significantly different by Fisher's protected least significant difference test $(\alpha=0.05)$. 
tion in the nursery in 2007 was 50 plants $/ \mathrm{m}^{2}$ compared with 67 plants $/ \mathrm{m}^{2}$ in 2008. In 2007, total plants per unit area varied significantly in each treatment, with progressively fewer runner plants in plots inoculated with increasing proportion of mother plants. In 2008, the number of runner plants at the 5\% level of inoculation and noninoculated control were statistically similar, and the 10 and $25 \%$ inoculation levels produced lower numbers of runner plants compared with the noninoculated control and 5\% inoculation level (Table 2).

Spatial dispersal gradient of $\boldsymbol{C}$. gloeosporioides in strawberry nurseries. Incidence of QI was high at the primary inoculation sites in both years, with $96.3 \%$ in 2007 and $100 \%$ in 2008, but was reduced to 26.3 and $33.8 \%$ at a 1-m distance in 2007 and 2008, respectively. The incidence of QI beyond $1 \mathrm{~m}$ showed a steady decline up to $4 \mathrm{~m}$. Although QI was detectable up to $7 \mathrm{~m}$, severity was extremely low (data not shown). In both years, the exponential model predicted a much steeper gradient for disease spread from the source (Table 3). Furthermore, although the correlations of observed and predicted values were similar for the two models, the coefficients of determination were slightly higher for the exponential model $\left(R^{2}=0.92\right.$ to 0.94$)$ than for the modified power law model $\left(R^{2}=0.89\right.$ to 0.90$)$. However, residual plots for the exponential model exhibited a less than random scatter, especially in 2008, compared with residual plots for the modified power law model (data not shown). The behavior of the residual plot indicated that the latter model was appropriate in describing dispersal gradient in this study. Despite a sharp decline of QI incidence at $1 \mathrm{~m}$ and beyond, dispersal gradient showed a linear relationship with distances from the point source of inoculum (Fig. 3).

\section{Discussion}

$\mathrm{ACR}$ is one of the most economically important diseases of strawberry and responsible for significant productivity and profitability losses. Results from this study indicated that $C$. gloeosporioides reduced runner plant density by 0.88 to 1.23 plants $/ \mathrm{m}^{2}$ (revealed by regression analysis of percent inoculation on plants per square meter) for every percent increase of inoculated mother plants. This is a direct loss to the nursery grower in productivity. Many nursery growers produce plugged plants for resale or sell tips that are used by a plug grower, and these enterprises may realize additional economic losses. We selected nonsymptomatic tips from the plots with the highest number of inoculated mother plants, grew plugs according to commercial standards, and experienced a 16.8 (2008) to $29.3 \%$ (2007) death rate.

Many of the epidemics in fruiting fields in the SE can be traced back to nursery infection of plants. Thus, studies aimed at improv-

Table 2. Effect of mother plants inoculation on the number of runner plant production in the strawberry nursery in 2007 and $2008^{z}$

\begin{tabular}{lllll}
\hline & \multicolumn{4}{c}{ Mean number of plants per square meter } \\
\cline { 2 - 5 } Inoculation level & $\mathbf{2 0 0 7}$ & $\mathbf{\pm S E}$ & $\mathbf{2 0 0 8}$ & $\pm \mathbf{S E}$ \\
\hline Noninoculated & $60.4 \mathrm{a}$ & 1.77 & $80.5 \mathrm{a}$ & 2.36 \\
5\% mother plants & $54.1 \mathrm{~b}$ & 0.88 & $76.0 \mathrm{a}$ & 1.52 \\
10\% mother plants & $46.6 \mathrm{c}$ & 0.88 & $60.5 \mathrm{~b}$ & 1.04 \\
$25 \%$ mother plants & $37.7 \mathrm{~d}$ & 2.6 & $50.2 \mathrm{~b}$ & 3.47 \\
\hline
\end{tabular}

${ }^{\mathrm{z}} \mathrm{SE}=$ standard error of means. Values with the same letter within each column are not significantly different from other values within the same year according to Fisher's protected least significant difference test $(\alpha=$ $0.05)$. ing the understanding of the disease cycle in the nursery should benefit both nursery and fruit growers. Nursery growers desire advanced understanding about the sources of inoculum, the level of risk infection foci present to the overall crop, and mitigation steps each operation can implement to reduce risk of disease. Oversummer soil survival of $C$. gloeosporioides indicates that it is unlikely for inoculum in the soil to become a major source for the next planting (43) in fruiting fields where back-to-back plantings are common. Thus, infection of healthy plants in the nursery from live sources in or around the nursery poses the most credible threat when nursery growers start their nursery with tissue-culturederived healthy plantlets. Infected plants may remain nonsymptomatic and use of these transplants acts as the major source of inoculum for fruiting field. C. gloeosporioides has been isolated from foliage of a wide range of introduced and native noncultivated plant species growing adjacent to strawberry fields in Florida that were implicated with inoculum source (45). Strawberry nurseries in general tend to have long rotation periods between crops and always start with clean micropropagated plants to meet certification standards. However, multiplication of tissue-cultured plants requires three to four generations prior to sale for fruit production. These field cycles present risk for inoculum exposure from alternative and noncultivated hosts. Mackenzie et al. (25) reported that sprinkler irrigation in the field during establishment of infested plants causes inoculum to spread into the crown from foliage, induces ACR, and results in establishment failure. Our results showed that nonsymptomatic foliage of noncultivated hosts harbored C. gloeosporioides, and $20 \%$ of these isolates were pathogenic to strawberry. Nursery surveys demonstrated that these species can be prevalent in close proximities around the nurseries in North Carolina, especially Virginia creeper. This species may present a significant risk because Virginia creeper was found to climb more than $20 \mathrm{~m}$ on huge pine trees adjacent to the surveyed nurseries. Isolated strains from Virginia creeper were more aggressive on strawberry compared with that of other noncultivated hosts. Observations in this study indicated that strawberry plants obtained the inoculum from alternative hosts, not vice versa, because clean plants from the same source remained free of detectable infection when planted distant from the alternative wild hosts. In most cases, C. gloeosporioides spreads by windblown rain or rain splash $(1,9,36)$. However, dispersal potential of inoculum from a noncultivated alternative host located at a higher elevation compared with the dispersal within a strawberry field is not known. In previous epidemics in commercial fields, proof linking noncultivated hosts to fruiting field ACR problems was documented using molecular tools (45). However, this study identified alternative hosts that may act as an initial source of $C$. gloeosporioides in North Carolina strawberry nurseries and the prevalence of $C$. gloeosporioides in these noncultivated species combined with proof of pathogenicity highlights the need for nursery growers to eradicate alternative hosts or avoid fields where alternative hosts may be prevalent.

Once $C$. gloeosporioides becomes established in a nursery, recurrent observations have shown that disease foci usually start as randomly located diseased plants in the field. This may be due to a random distribution of nonsymptomatic mother plants at the time of planting in a new cycle of plant multiplication in a nursery followed by dispersal to adjacent runner plants. In both years of this study, mother plants had higher QI incidence compared with runner plants. Gordon et al. (16) reported a differential infection of

Table 3. Dispersal gradient model parameters estimated by regression analysis of primary quiescent infection incidence data obtained from nursery leaves collected at different distances from the source and subjected to paraquat dip protocol to grow out Colletotrichum gloeosporioides ${ }^{z}$

\begin{tabular}{|c|c|c|c|c|c|c|c|c|}
\hline \multirow[b]{2}{*}{ Model } & \multicolumn{4}{|c|}{2007} & \multicolumn{4}{|c|}{2008} \\
\hline & $a$ & $b$ & $R^{2}$ & $r$ & $a$ & $b$ & $R^{2}$ & $r$ \\
\hline Exponential & 77.09 & -0.54 & 0.94 & 0.97 & 68.37 & -0.57 & 0.92 & 0.96 \\
\hline Modified power law & 23.57 & -0.34 & 0.89 & 0.94 & 19.57 & -0.37 & 0.90 & 0.95 \\
\hline
\end{tabular}

${ }^{\mathrm{z}}$ Parameter $a$ denotes the amount of inoculum present at the source point, while parameter $b$ denotes the slope of the gradient. $R^{2}$ denotes the coefficient of determination, while $r$ denotes Pearson correlation coefficient between observed and predicted disease values. 
mother and runner plant generations in a strawberry nursery by soilborne fungal organism Verticillium dahliae. Dispersal of inoculum from mother to runner plants within a nursery setting at 60 DAI was very high around the mother plants but long-range dispersal from infected mother plants (source of inoculum) was restricted to about $4 \mathrm{~m}$. A steep dispersal gradient obtained from the empirical models is in agreement with the hypothesis that rogueing infected plants in and around infection foci will remove most of the infected plants with higher QI severity, thereby reducing economic losses to the local nursery and fruiting fields. Nursery growers may also treat plants harvested farther from such foci using curative fungicides (24) to fulfill consumers' fruiting field plant needs.

The plug production phase requires constant misting during the rooting period, which results in splash dispersal of spores to adjacent plugs that also become infected but may remain nonsymptomatic after the 4-week production cycle (data not shown). The importance and role of QIs is a challenge to the industry, certification inspectors, and scientific personnel but its importance was recognized by other investigators $(22,30)$. This study utilized QI for both infection incidence and severity in the absence of any visible symptom. Some inoculated mother plants showed diagnostic black spots but symptom expression did not appear to show any correlation with proportion of mother plant inoculations. In general, infection of leaves with a highly aggressive C. gloeosporioides strain under high humidity is expressed by irregular black spots. However, our data on black spot (not shown) and QI suggested that black spot may not be a reliable indicator of C. gloeosporioides foliar infection and dispersal in strawberry nurseries. In a similar study, however, Okayama (32) reported a moderate correlation of the number of black leaf spots with the concentration of conidia in the inoculum used for investigating the effect of barriers on rain splash dispersal of $C$. gloeosporioides from infected strawberry plants. This discrepancy in the appearance of black spots might be due to the difference in the isolates, weather conditions, or geographical locations where the studies were conducted.

QI is a well-known phenomenon in anthracnose diseases, especially on foliage (15), and, thus, a valid evaluation of the prevalence of inoculum in foliar tissues will need QI assessment (30) by a traditional paraquat protocol complemented with a highly sensitive DNA-based method (35). Differences in QI incidence, severity, and dispersal of inoculum in 2007 and 2008 may have been linked to the prevailing temperature and rainfall patterns, especially during the period from inoculation to sampling for QI in the nursery. Wetness hours (usually affected by rainfall and relative humidity) and temperatures were found directly correlated with germination, secondary conidiation, and appressorial formation of $C$. acutatum on symptomless strawberry leaves (22). Similar survival and inoculum multiplication mechanisms may be operative for $C$. gloeosporioides on strawberry foliage. The importance of high temperature $\left(>25^{\circ} \mathrm{C}\right)$ and humidity (relative humidity near $\left.100 \%\right)$ for disease development in strawberry plants infected with $C$. fragariae was shown by many investigators both in the field $(9,36)$ as well as in the greenhouse $(38,39)$.

We fitted dispersal data in two of the most common empirical models (13) and there were no significant differences in either the coefficients of determination or residual plot-based goodness-offit, although the exponential model had a slightly higher coefficient of determination and power law model had a slightly improved residual plot. It corroborates the observation by Esker et al. (12) that, in many cases, where one of these models provides a good fit to data, the other may fit almost as well. Aylor (2) also mentioned that, for a variety of crops, pathogens, and conditions, deposition gradients can often be fitted equally well by either an exponential or a power of $x$ (12), particularly if the range of $x$ is limited. Bodreau et al. (3) found that dispersal of $C$. acutatum within strawberry rows from infected fruit placed as a source under simulated rain conditions could be described well by the exponential model. However, this dispersal was evaluated from the deposited spores in petri plates containing PDA and preset at specified distances from the source (3), compared with the evaluation of latent infections in strawberry leaves in our study. Plant disease spread and focus expansion can be analyzed with more complicated mathematical models as well $(1,28,44)$. Parker et al. (33), studying rain splash dispersal of Septoria lycopersici in a tomato field from the source to $1.8 \mathrm{~m}$, demonstrated that the infection steeply decreased with increasing distance, and data from individual disease gradients were best described by the regression of nontransformed area under curve values with distance from the source. When data from a dispersal study of $C$. gloeosporioides $\mathrm{f}$. sp. aeschynomene in rice fields was integrated by Yang et al. (46) using a power law model, dispersal of the pathogen was significantly reduced with the presence of weeds within the rice canopy. In addition, high rice density not only reduced the steepness of the dispersal gradient but also reduced the intercept of the dispersal curve $(46,47)$. In our study, the strawberry nursery remained weed free due to preplanting herbicide treatment of the experimental plot and dispersal may have not been influenced by this factor. Ntahimpera et al. (31) demonstrated that closely related Colletotrichum spp. were similar in terms of splash dispersal from infected fruit of the same plant species (Fragaria $\times$ ananassa). The challenge is that many infections may not appear as symptomatic plants with distinct foci because the pathogen can persist and likely disperse from QI, potentially similar to $C$. acutatum (21). Despite very different weather patterns in 2007 and 2008, the dispersal gradients were remarkably similar, perhaps because the reliance on overhead watering to sustain plant growth in the absence of rain (goal of $2.5 \mathrm{~cm}$ per week) may have normalized dispersal gradients. One plausible explanation for limited distance dispersal is that the strawberry canopy
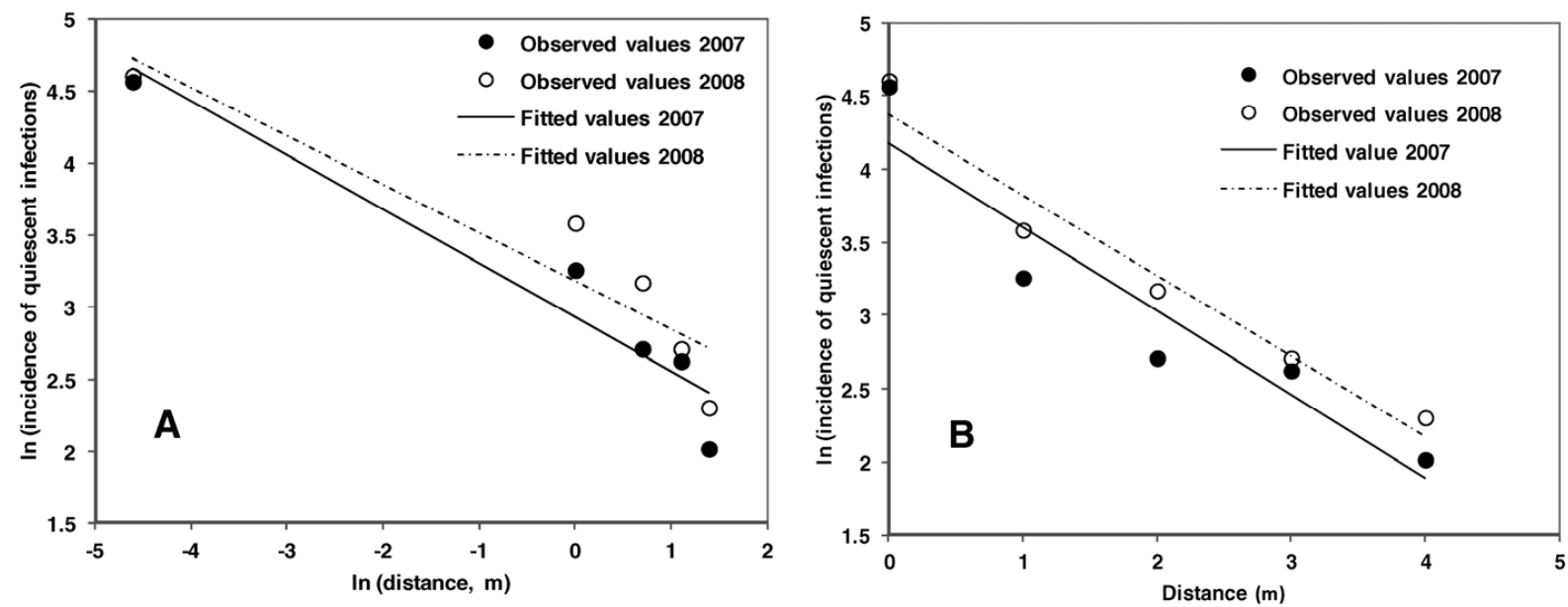

Fig. 3. Linear regression fit of Colletotrichum gloeosporioides dispersal gradient data from the strawberry nurseries in 2007 and 2008 ; A, exponential model and B, modified power law model. Symbols (closed or open) represented observed data and lines (continuous or dashed) represented predicted values. 
height was only approximately $0.25 \mathrm{~m}$ and, at the inoculation stage, there was barren ground around mother plants that got covered by runner plants over time. Previous studies on Colletotrichum spp. found that dispersal distance was inversely proportional to surface roughness $(46,47)$ and plant density (3). Soil surface in the above comparative study provided a relatively steep curve compared with that from a smoother water surface. Results from our study concur with the results obtained by Okayama (32) on rain dispersal patterns of $C$. gloeosporioides in strawberry, who reported that disease incidence on leaflets and petiole was severe within half a meter horizontally from the inoculum source, although conidia were disseminated more than $3 \mathrm{~m}$ in heavy rain.

This study highlighted the potential importance of alternative hosts that may harbor pathogenic strains of $C$. gloeosporioides, and demonstrated that dispersal within nurseries from infected foci was associated with steep gradients and that nonsymptomatic plants can harbor the pathogen and cause plug plant mortality. This knowledge is an important component toward development of detection and sampling protocols and integrated management systems to reduce risk of ACR in commercial nurseries and fruiting fields.

\section{Acknowledgments}

We thank Z. Pesic-Van Esbroeck for providing planting stocks for this study; J. Driver and M. Carnes for their help with the field work; and the Horticultural Crops Research Station, Clinton, NC for outstanding support for field experiments. This research was funded by a grant awarded to F. Louws by the Southern Region IPM program contract number 2005-34103-16018 and support from the NC-Strawberry Growers Association and North American Strawberry Growers Association.

\section{Literature Cited}

1. Agostini, J. P., Timmer, L. W., and Gottwald, T. R. 1993. Temporal and spatial dynamics of postbloom fruit drop of citrus in Florida. Phytopathology 83:485-490.

2. Aylor, D. E. 1987. Deposition gradients of uredinospores of Puccinia recondita near source. Phytopathology 77:1442-1448.

3. Boudreau, M. A., and Madden, L. V. 1995. Effects of strawberry density on spore dispersal of Colletotrichum acutatum by simulated rain. Phytopathology 85:934-941.

4. Bowman, D. T. 2000. TFPlan: Software for restricted randomization in field plot design. Agon. J. 92:1276-1278.

5. Brooks, A. N. 1931. Anthracnose of strawberry caused by Colletotrichum fragariae, n. sp. Phytopathology 21:739-744.

6. Campbell, C. L., and Madden, L. V. 1990. Introduction to Plant Disease Epidemiology. Wiley, New York.

7. Cannon, P. F., Bridge, P. D., and Monte, E. 2000. Linking the past, present, and future of Colletotrichum systematics. Pages 1-20 in: Colletotrichum: Host Specificity, Pathology, and Host-Pathogen Interaction. D. Prusky, S. Freeman, and M. B. Dickman, eds. American Phytopathological Society, St. Paul, MN.

8. Cerkauskas, R. F., and Sinclair J. B. 1980. Use of paraquat to aid detection of fungi in soybean tissue. Phytopathology 70:1036-1038.

9. Chakraborty, S., and Billard, L. 1995. Quantitative relationship between Colletotrichum gloeosporioides infection of Stylosanthes scabra and weather under field conditions. Plant Pathol. 44:63-72.

10. Delp, B. R., and Milholland, R. D. 1981. Susceptibility of strawberry cultivars and related species to Colletotrichum fragariae. Plant Dis. 65:421-423.

11. Durner, E. F., Poling, E. B., and Maas, J. L. 2002. Recent advances in strawberry plug transplant technology. HortTechnology 12:545-550.

12. Esker, P. D., Sparks, A. H., Antony, G., Bates, M., Dall' Acqua, W., Frank, E. E., Huebel, L., Segovia, V., and Garrett, K. A. 2007. Ecology and Epidemiology in R: Modeling dispersal gradients. Plant Health Inst. doi:10.1094/PHI-A-2007-1226-03

13. Fitt, B. D. L., Gregory, P. H., Todd, A. S., and McCartney, H. A. 1987. Spore dispersal and plant disease gradients; a comparison between two empirical models. J. Phytopathol. 118:227-242.

14. Fitzell, R. D., and Peak, C. M. 1984. The epidemiology of anthracnose disease of mango: Inoculum sources, spore production and dispersal. Ann. Appl. Biol. 104:53-59.

15. Freeman, S., Horowitz, S., and Sharon, A. 2001. Pathogenic and nonpathogenic lifestyles in Colletotrichum acutatum from strawberry and other plants. Phytopathology 91:986-992.

16. Gordon, T., Kirkpatrick, S., Shaw, D., and Larson, K. 2002. Differential infection of mother and runner plant generations by Verticillium dahliae in a high elevation strawberry nursery. HortScience 37:927-931.

17. Gunnell, P. S., and Gubler, W. D. 1992. Taxonomy and morphology of Colletotrichum species pathogenic to strawberry. Mycology 84:157-165.

18. Horn, N. L., and Carver, R. G. 1963. A new crown rot of strawberry plants caused by Colletotrichum fragariae. Phytopathology 53:768-770.

19. Howard, C. M., and Albregts, E. E. 1983. Black leaf spot phase of strawber- anthracnose caused by Colletotrichum gloeosporioides $(=C$. fragariae $)$ Plant Dis. 67:1144-1146.

20. Howard, C. M., and Albregts, E. E. 1984. Anthracnose of strawberry fruit caused by Glomerella cingulata in Florida. Plant Dis. 68:824-825.

21. Kiyosawa, S., and Shiyomi, M. 1972. A theoretical evaluation of the effect of mixing resistant variety with susceptible variety for controlling plant diseases. Ann. Phytopathol. Soc. Jpn. 38:41-51.

22. Leandro, L. F. S., Gleason, M. L., Nutter, F. W., Wegulo, S. N., and Dixon, P. A. 2003. Influence of temperature and wetness duration on conidia and appressoria of Colletotrichum acutatum on symptomless strawberry leaves. Phytopathology 93:513-520.

23. Legard, D. E., Whidden, A. J., and Chandler, C. K. 1998. Incidence and occurrence of strawberry diseases in Florida from 1991-1996. Adv. Strawberry Res. 16:35-47.

24. MacKenzie, S. J., Legard, D. E., Timmer, L. W., Chandler, C. K., and Peres, N. A. 2006. Resistance of strawberry cultivars to ACR caused by Colletotrichum gloeosporioides isolates from Florida is nonspecific. Plant Dis. 90:1091-1097.

25. MacKenzie, S. J., Mertely, J. C., and Peres, N. A. 2009. Curative and protectant activity of fungicides for control of ACR of strawberry caused by Colletotrichum gloeosporioides. Plant Dis. 93:815-820.

26. McInnes, T. B., Black, L. L., and Gatti, J. M., Jr. 1992. Disease-free plants for management of strawberry anthracnose. Plant Dis. 76:260-264.

27. Mills, P. R., Sreenivasaprasad, S., and Brown, A. E. 1992. Detection and differentiation of Colletotrichum gloeosporioides isolates using PCR. FEMS Microbiol. Lett. 98:137-144.

28. Minogue, K. P., and Fry, W. E. 1983. Models for the spread of plant disease: Model description. Phytopathology 73:1169-1173.

29. Mundt, C. C., and Leonard, K. J. 1985. A modification of Gregory's model for describing plant disease gradients. Phytopathology 75:930-935.

30. Nam, M. H., Lee, I. H., Kwon, K. H., and Kim, H. G. 2004. Significance and detection of quiescent infection of Colletotrichum gloeosporioides on strawberry. Kor. J. Hortic. Sci. Technol. 22:294-297.

31. Ntahimpera, N., Wilson, L., Ellis, M., and Madden, L. 1999. Comparison of rain effects on splash dispersal of three Colletotrichum species infecting strawberry. Phytopathology 89:555-563.

32. Okayama, K. O. 1994. Effect of barrier on rain splash dispersal of Colletotrichum gloeosporioides from infected strawberry plant. Ann. Phytopathol. Soc. Jpn. 60:113-118.

33. Parker, S. K., Gleason, M. L., and Nutter, F. W., Jr. 1995. Influence of rain events on spatial dispersal of Septoria leaf spot of tomato. Plant Dis. 79:148-152.

34. Prusky, D., and Lichter, A. 2008. Mechanisms modulating fungal attack in post-harvest pathogen interactions and their control. Pages 281-289 in: Sustainable Disease Management in a European Context. D. B. Collinge, L. Munk, and B. M. Cooke, eds. Springer, New York.

35. Rahman, M., Carnes, M. E., and Louws, F. J. 2009. Real-time PCR systems aid in quantitative detection of Colletotrichum spp. in spatial dispersal studies of strawberry anthracnose. (Abstr.) Phytopathology 99:S107.

36. Rajasab, A. H., and Chawda, H. T. 1994. Dispersal of the conidia of Colletotrichum gloeosporioides by rain and the development of anthracnose on onion. Grana 33:162-165

37. Smith, B. J. 2008. Epidemiology and pathology of strawberry anthracnose: A North American perspective. HortScience 43:69-73.

38. Smith, B. J., and Black, L. L. 1987. Resistance of strawberry plants to Colletotrichum fragariae affected by environmental conditions. Plant Dis. 71:834-837.

39. Smith, B. J., and Spiers, J. M. 1982. Evaluating techniques for screening strawberry seedlings for resistance to Colletotrichum fragariae. Plant Dis. $66: 559561$

40. Sreenivasaprasad, S., Brown, A. E., and Mills, P. R. 1992. DNA sequence variation and interrelationships among Colletotrichum species causing strawberry anthracnose. Physiol. Mol. Plant Pathol. 41:265-281.

41. Sreenivasaprasad, S., Mills, P. R., Meehan, B. M., and Brown, A. E. 1996 Phylogeny and systematic of 18 Colletotrichum species based on ribosomal DNA spacer sequences. Genome 39:499-512.

42. Ureña-Padilla, A. R., MacKenzie, S. J., Bowen, B. W., and Legard, D. E 2002. Etiology and population genetics of Colletotrichum spp. causing crown and fruit rot of strawberry. Phytopathology 92:1245-1252.

43. Urena-Padilla, A. R., Mitchell, D. J., and Legard, D. E. 2001. Oversummer survival of inoculum for Colletotrichum ACR in buried strawberry crown tissue. Plant Dis. 85:750-754.

44. Van den Bosch, F., Zadoks, J. C., and Metz, J. A. J. 1988. Focus expansion in plant disease. II: Realistic parameter-sparse models. Phytopathology 78:59-64.

45. Xiao, C. L., MacKenzie, S. J., and Legard, D. E. 2004. Genetic and pathogenic analyses of Colletotrichum gloeosporioides isolates from strawberry and non-cultivated hosts. Phytopathology 94:446-453.

46. Yang, X., and Teebest, D. O. 1990. Rain dispersal of Colletotrichum gloeosporioides in simulated rice field conditions. Phytopathology 82:1219-1222.

47. Yang, X. B., and Tebeest, D. O. 1992. Analysis of dispersal mechanisms and spatial distribution of Colletotrichum gloeosporioides $\mathrm{f}$. sp. aeschynomene in rice. Phytopathology 82:1079-1082. 